\title{
Relationship between Economic and Socio-cultural Resilience of Rural Settlements after Suffering from Earthquake \\ (A case study: Rural Settlements of Silakhor District in Dorud)
}

\section{Afsaneh Hassanvand ${ }^{1}$, Ali Hajinejad ${ }^{2}$, Majid Yasouri ${ }^{3}$}

Date of submission: 04 Jul. 2019 Date of acceptance: 29 Dec. 2019

\begin{abstract}
INTRODUCTION: Natural disasters in rural settlements are responsible for a broad range of financial and human losses. In this regard, the resilience approach has gained renewed attention to minimize the disruptive impacts of natural catastrophes. Therefore, adequate knowledge about the status of resilience enables us to take efficient measures to reduce resultant injuries and destructive effects. With this background in mind, the current study aimed to investigate the relationship between economic and socio-cultural resilience of rural settlements in Silakhor rural district in Dorud.

METHODS: This practical study was conducted based on an analytical-descriptive design. The statistical population included 1539 earthquake-stricken households of Silakhor village (according to household information from the 2016 Census). Out of this population, 308 families were selected as the sample size using the Cochran's formula. The validity of the questionnaire was confirmed by a panel of experts, and its reliability was evaluated using Cronbach's alpha method rendering the coefficients of 0.910 and 0.854 for the economic and socio-cultural dimension, respectively. One-Sample T-Test and Pearson correlation were used to examine the status of resilience and the relationship between economic resilience and sociocultural resilience.
\end{abstract}

Original Article

FINDINGS: As evidenced by the obtained results, rural settlements were socio-culturally resilient with the mean score of $>3$, while they were somewhat resilient in the economic dimension with the mean score of nearly 3 .

CONCLUSION: The results of the Pearson correlation pointed to a positive and significant relationship between economic and social resilience with a correlation coefficient of 0.420 and a significance level of $\mathrm{P}<0.00$.

Keywords: Economic Resilience; Natural Disasters; Resilience; Silakhor Rural District; Sociocultural Resilience.

How to cite this article: Hassanvand A, Hajinejad A, Yasouri M. Relationship between Economic and Socio-cultural Resilience of Rural Settlements after Suffering from Earthquake (A case study: Rural Settlements of Silakhor District in Dorud). Sci J Rescue Relief 2019; 11(4): 225-37.

\section{Introduction}

A cursory look at the history of life on Earth shows that humans have been always exposed to a myriad of natural disasters. Some of these events are related to climatic factors and fluctuations, such as droughts, floods, and earthquakes, which have occurred at different times leading to deadly consequences (1). Natural hazards are key challenges to achieving sustainable development and are considered as formidable barriers to economic, social, and civil development. National development programs

1-MA, Geography and Rural Planning, University of Guilan, Guilan, Iran 2-PhD, Geography and Rural Planning, University of Guilan, Guilan, Iran 3-PhD, Geography and Rural Planning, University of Guilan, Guilan, Iran Correspondence to: Afsaneh Hassanvand, Email: a.hassanvand94@gmail.com 
will face more serious problems if these natural disasters get worse (2). Since the beginning of life, disasters have exerted negative impacts on human life. In response, individuals and communities have sought to reduce the consequences of these disasters and establish scales to assess the initial effects.

Natural disasters have always existed as a recurring phenomenon throughout human life and will continue to exist in the future. Such naturally occurring events as floods, earthquakes, and hurricanes have often had devastating effects on human settlements and inflicted heavy losses on them in most cases. It can be stated that despite the advances in science in many areas of natural disasters, they are still regarded as uncontrollable phenomena (3). The management of these events is one of the main challenges faced by most countries since they not only cause death and emotional suffering but also damage local economics and puts development gains at risk.

According to United Nations International Strategy for Disaster Reduction (UNISDR), natural catastrophes have inflicted an economic loss of 600 billion dollars in various countries in recent years and affected more than 3 billion people out of whom more than 750,000 have lost their lives. The rising cost of natural disasters, along with the resulting threats, has made countries improve disaster preparedness (4). Concurrently, rural communities and related manufacturing activities have long been exposed to natural destructive forces more than other communities due to their close relationship with the natural environment and their limited ability to deal with environmental threats (5).

Natural disasters, especially earthquakes, have exerted devastating effects on all functionalstructural aspects of rural settlements, including their economic functioning. These disasters endanger the health of the residents and inflict heavy losses on them by destroying the sources of income and biological facilities of the rural settlements. They destroy the buildings and infrastructures in these areas and impose farreaching economic and social consequences on human societies (6). Today, governments adopt various strategies to reduce the effects of natural hazards. One of these approaches is resilience to natural hazards, and one of the most effective solutions in this regard is the identification and management of hazards by members of society and assessment of resilience.

Today, the perspectives and theories of disaster management and sustainable development seek to create resilient communities against natural hazards. Disaster resilience represents a key issue for contemporary society. It was first introduced in Hyogo Framework by the International Union for Disaster Risk Reduction Strategy and is currently considered one of the international tools and policies. Resilience to natural disasters in urban and rural areas is not the same. Due to their mono-product economy, rural areas are normally dependent on the government to maintain their business and do not have the capacity for additional resources needed during and after the disaster (2).

It is of utmost importance to strengthen the resilience of communities and residents to cope with the challenges and shocks inflicted by disasters since resilient communities have a great capacity to recover from natural disasters and withstand future side effects more efficiently (7). The rural settlements of Silakhor village were exposed to a magnitude 6 earthquake on March 31, 2006 which had negative impacts on the economy and human life in varying degrees. Despite the importance of this issue, no comprehensive study has so far been conducted in the region to assess the socio-cultural and economic resilience of the settlements in this region and examine the relationship between economic and socio-cultural factors in these settlements. Therefore, the present study aimed to assess the relationship between economic resilience and socio-cultural resilience of rural settlements in Silakhor district of Dorud and seeks to answer the following questions:

1. What is the economic and social resilience status of rural settlements in Silakhor district?

2. How ware economic and social resilience of rural settlements in Silakhor rural district related?

\section{Theoretical foundations of research}

The hazards and damages inflicted by natural disasters are on a rise across the globe leading to adverse physical, economic, and social impacts, loss of life and property, as well as total destruction of resources (8). Earthquake as one of the natural phenomena has terrified human beings throughout the history of mankind. This natural catastrophe is responsible for the destruction of cities and villages, along with severe human 
losses and suffering. Humans have always sought supernatural explanations for natural disasters and regarded them as the wrath of gods.

Crisis and disaster management of hazards is a relatively new comprehensive approach which examines all the catastrophes society may face. However, the majority of the concepts that guide current activities hinge on the successes of previous civilizations. Nonetheless, disaster management over the past few thousand years has been limited to a few activities or programs that addressed individual hazards. Many of these activities, such as the reduction of human suffering and damage to buildings, have been comprehensive and effective (9).

In general, there are two types of strategies for dealing with natural disasters: predictive strategies and coping strategies. The first strategy is used to deal with recognized problems and difficulties, and the second one is developed to cope with unfamiliar problems. In the meantime, resilience signifies the improvement of society skills, planning, and preparedness for absorption, improvement, and more success in dealing with the unintended consequences of disasters, as well as social, economical, and environmental improvement of disaster-stricken society.

Accordingly, the link between community development and disaster management is indispensable for the establishment of a resilient society against hazards. Community-based planning and assessment of risks and hazards is the fundamental first step in building community resilience. Programs should be reviewed regularly and updated based on information, new experiences, and knowledge gained from implementation and monitoring. Therefore, resilience should be the central concept of all development and disaster management programs in the community (10). Therefore, as stated by numerous researchers, resilience is the key to achieving sustainability. It is recognized as a major contribution to strengthen communities with the help of their capacities, and different definitions, approaches, indicators, and measurement models have been proposed for this concept (11).

The word resilience was derived from the Latin word resilio meaning "springing back." Resilience also refers to the ability to resist, absorb, accommodate to, and recover from the effects of a hazardous event in a timely efficient and manner
(12). The term resilience first emerged as an ecological concept in social systems in 1973 following the publication of Holling's original work entitled "Resilience and Sustainability of Ecological Systems. Nevertheless, theoretical foundation and literature review of related studies suggest that the study of resilience was inferred from the psychological and psychiatric practices of the 1940s, much of which was developed by Norman Gramsci, Amy Wenner, and Roth Smith (13).

In economics, resilience is defined as the inherent response and adaptation of individuals and societies to hazards in a way that enables them to reduce the resultant damages and loss (10). Regional economics which is harder hit by shocks are more likely to recover, compared to economic resilience which is severely affected by shocks. Economic resilience is the inherent response or adaptation of individuals, market, and market economy to hazards. In fact, economic resilience is the economic vitality and prosperity of society. Social resilience is a function of demographic characteristics and access to resources (14).

Social resilience is defined as "the ability of a society to cope and return to past relying on its own resources." Social resilience draws upon internal resources and competencies to manage the demands, challenges, and changes encountered (8). The concept of community resilience to hazards and accidents is defined as the capacity of a system or part of it to absorb and recover from hazardous events (15). Recent approaches to resilience can be summarized into three main approaches: resilience as sustainability, resilience as recovery, and resilience as transformation. Common to all of them is the ability to withstand, resist, and react positively to pressure or change.

The sustainability approach to resilience is developed from ecological studies that define resilience as the ability to return to the previous level of functioning. This approach defines resilience as the magnitude that a system can resist or absorb before it shifts to another state. Some researchers consider a threshold beyond which a disaster-stricken society is unable to return to its functional state since a resilient society has a high threshold and is able to absorb a lot of pressure before it exceeds its threshold. The recovery approach to resilience is related to society's ability to get away from change or 
pressure and bounce back to normal.

Resilience is an indicator measured as the time a society spent recovering from change. Resilient society is able to return to its previous state relatively quickly, while a less resilient society may spend more time recovering or may not be able to recover at all. The approach of resilience as a further transformation in relation to social resilience is the capacity of society to adaptively react to change. This approach states that instead of simply returning to the initial state, society can change to a new situation which is more stable in the existing environment.

The transformational approach to resilience is effective for gaining insights on how a society can positively react to change, accepting that change is inevitable. Based on this perspective, communities need change to return to their initial state. The transformation approach accepts the dynamic nature of societies, as well as humanecosystem interactions and multiple potential pathways within them (16). Among the conceptual approaches, the two approaches of sustainability and recovery have a definite understanding of resilience. Both of them consider the resilience of a society (individual or ecological system) to be an inherent characteristic enabling them to adapt to pressure.

These two approaches emphasize that society as a whole is either resilient or not resilient. Nonetheless, the third approach, resilience as transformation, highlights the difference between social and ecological resilience. Social resilience considers the capacity of individuals to learn from experiences and consciously participate in learning in interaction with the social and physical environment. Moreover, this approach seeks to identify the dynamic characteristics of societies and the interaction between humans and ecosystems and focuses on its adaptive capacities instead of the vulnerability of society (17).

According to the abovementioned issues and studies conducted in this regard, the effective economic and social factors involved in the resilience of rural settlements can be reported in the form of an experimental model (Figure 1).

Given the reality of natural disasters and how and why they occur, it can be argued that such disasters can never be eliminated; therefore, the consequences of these disasters must be reduced

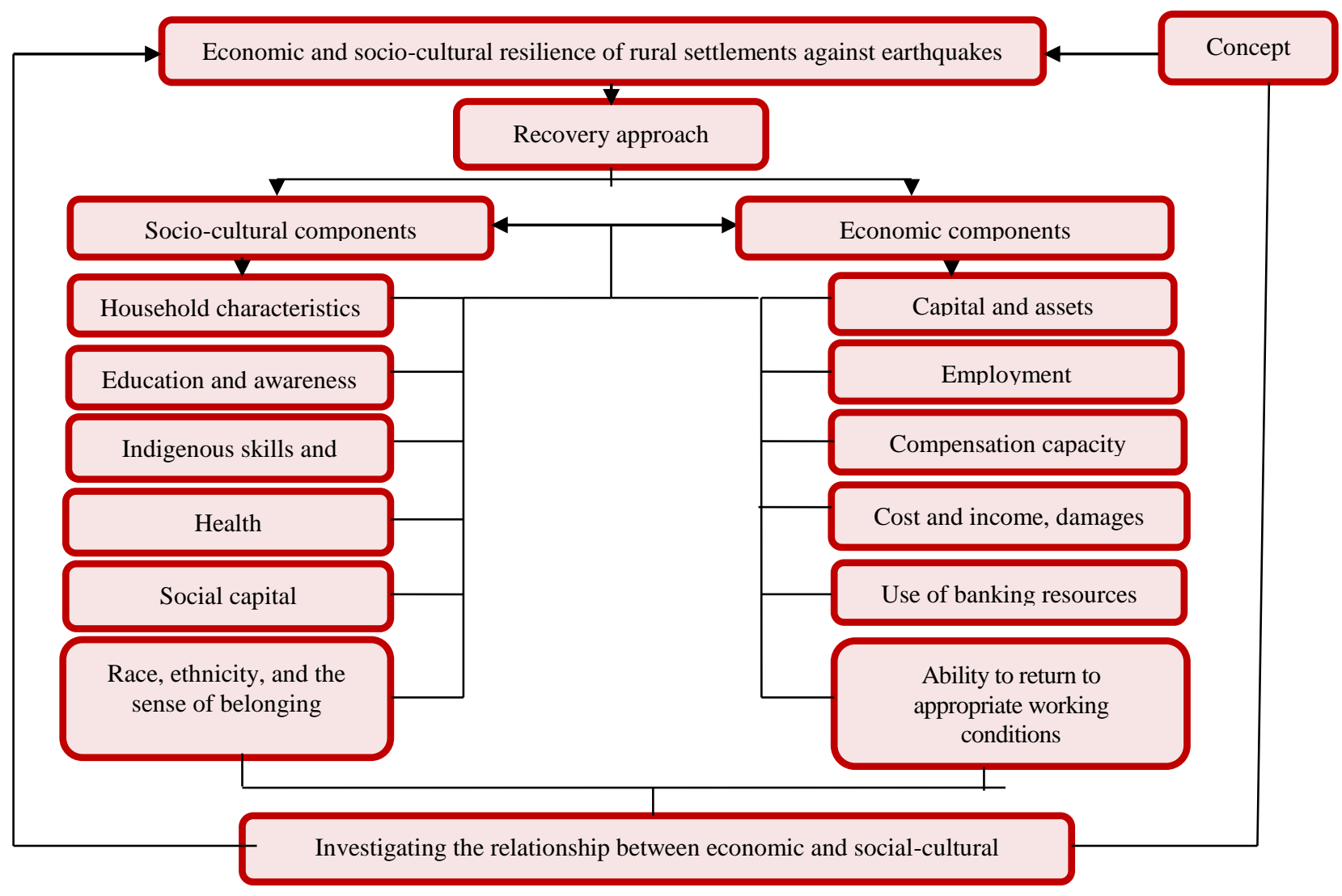

Figure 1. Experimental model of research (Source: research findings, 2017) 
with proper planning. Therefore, the recovery approach was adopted for the present study regarding the planning dimension to accelerate the return to equilibrium, emphasis on theoretical foundations, previous studies, experiences of different countries, and the general purpose of the research to assess the relationship between sociocultural and economical resilience.

This approach was selected due to the following reasons:

- Recovery does not merely lead to restoration rather it requires processes that are influenced by common socio-economic conditions to restore society to its original foundations.

- In this approach, local participation is a prerequisite for any success; therefore, the current approach emphasizes the accumulation of capital and assets, local participation, resources, local and governmental policies and programs, and social capital.

The recovery approach has a definite understanding of resilience and refers to the resilience of a community to "bounce back to normal" from pressure and return to its original state. In the recovery approach, resilience is looked upon as an intrinsic feature of a society emphasizing that a society as a whole is either resilient or not resilient. In this approach, resilience is measured as the time spent by a society to recover from change. A resilient society is able to return relatively quickly to its previous state, while a less resilient society may spend more time recovering or may not be able to recover at all.

\section{Review of literature}

To the best of our knowledge, so far, no study has been conducted on the subject of the present study. However, various related studies have been performed as follows:

Shokri Firouzahah carried out a study entitled "Spatial Analysis of Resilience of Babol City Against Environmental Hazards "(2017) (18). This article aimed to investigate the resilience of regions of Babol against environmental hazards. The present study adopted a descriptive-analytical design and used a questionnaire which consisted of four dimensions (social, physical, economic, institutional), 66 indicators, and 96 sub-indicators. In this regard, 383 questionnaires were randomly distributed among the participants based on Cochran's model.
Vikor multivariate decision model has been used to investigate the research problems and analyze the data. The standard weight of each index was calculated using Shannon's entropy method. The obtained data were analyzed in SPSS, GIS, and Excel software revealing that among the various dimensions of urban resilience in the 62 districts of Babol, the physical dimensions with a mean score of 9.44 had a better status, followed by social dimension with a mean score of 9.64 .

Nonetheless, in general, about $45 \%$ of the surveyed areas in Babol have no resilience and low resilience, and only $24 \%$ of the areas are completely resilient in terms of indices. Roknoddin Eftekhari et al. performed a study entitled "Analysis of Livelihoods Diversity in Resilience of Rural Households under Drought Conditions, Case Study: Areas Exposed to Drought in Isfahan Province, Rural Studies" in 2014 (19). The mentioned study aimed to analyze the diversity of livelihood in the resilience of farming households in drought-prone areas of Isfahan.

This quantitative survey adopted an analyticaldescriptive design and used correlation relations. The studied indicators included social, economic, psychological, physical, and ecological dimensions. The results of the study denoted that adopting a livelihood diversity approach has led to more resilient households in drought conditions, and this diversity is more evident in villages that are more exposed to severe drought.

Ramezanzadeh Lesboui et al. (1393) examined infrastructure and resilience against natural disasters (Study area: Typical Tourism Regions in North of Iran (Cheshmekile \& Sardabrud) (20). The main purpose of this study was to investigate the infrastructure components in order to improve the resilience of residents to natural disasters. This practical research was conducted based on a descriptive-analytical design. The obtained data were analyzed in SPSS software using statistical tests. Research variables included infrastructure (communication networks, locating service and medical centers) as independent variables and also two dimensions of individual and social resilience as dependent variables.

The results demonstrated that the flood management infrastructures and resilience with 99\% confidence increase the resilience of residents to natural disasters (floods). Moreover, a significant difference was observed between the 
two fields in terms of infrastructure components and resilience to natural disasters (flood). Ainuddin and Routray conducted a study entitled "Community resilience framework for an earthquake-prone area in Baluchistan". The mentioned study aimed to investigate and provide a resilience framework for communities at risk of natural disaster. The present study was conducted based on qualitative and quantitative designs. The results of the study led to the presentation of a new framework of resilience which will enhance awareness, community preparedness, and ultimately resilience at the local level (21).

The results of a study performed by Kafle (2011) entitled " Measuring disaster-resilient communities: A case of coastal communities" yielded the main elements of resilience. They include a community based on volunteer training institutions and organizations, hazards, vulnerability, and assessed community capacity, development of risk reduction programs by formulating and implementing them, the involvement of women, children, and vulnerable groups in the development of risk reduction programs, integration of community and local programs, public awareness-raising about key hazards, the private sector and NGOs, external support, and alert systems (22).

Arouri et al. (2014) conducted a study entitled "Study of natural disasters, home welfare, and resilience among rural households in Vietnam". This study aimed to assess the effects of natural disasters on the welfare and poverty of rural households in Vietnam using fixed effects regression. In this study, after the assessment of family and social characteristics that can strengthen and improve the resilience to natural disasters, three types of natural hazards, including flood, storm, and drought, were investigated. The results demonstrated that all three types of hazards have negative effects on household income and expenditure. Moreover, it was found that families with higher costs and distribution are more resilient, and disadvantaged households in poor areas with limited access to financial resources are more vulnerable and less resilient.

Studies also denoted that strengthening security programs and access to microcredit, domestic remittances, or social allowance can help improve and strengthen the resilience of poor families to natural disasters (23). Kusumastuti et al. (2014) conducted a study entitled "Creating a
Disaster Resilience Index in Indonesia". The mentioned study aimed to create a framework and expand resilience in disaster-prone areas in Indonesia. It is required to assess resilience in disaster-prone areas to minimize the adverse effects of disasters and shorten the recovery period. The studied components included social, economic, and organizational dimensions, community capacity, as well as infrastructure, in Jakarta and Padang. The results demonstrated that both communities had high resilience to natural disasters and can achieve greater resilience in better conditions.

\section{Methods}

This practical study was conducted based on an analytical-descriptive design. Data were collected by library research and field study. In the library method, scientific sources and documents, such as books, articles and magazines, statistics, dissertations, and online sources were used to collect the required information.

In the field study, the most important data collection tool was the questionnaires which were administered to families in the region. The statistical population included 1539 households of Silakhor Rural District (according to household information from the 2016 Census). Out of this population, 308 families were selected as the sample size using the Cochran's formula. The mentioned rural district was selected for the study since it was the epicenter of the earthquake, and the highest amount of damage was related to the villages of this district. The participants were selected using random sampling.

The ratio and percentage of each village were calculated based on the number of households in the total statistical population (rural district). According to the proportion of the population of each village, the percentage and ratio of that village in the sample were determined. Thereafter, the households were selected using simple random sampling. The results are presented in Table (1) in the appendix.

The indicators studied in this study included the economic dimension with eight indicators and the socio-cultural dimension with seven indicators. These variables were extracted by an extensive review of related theoretical studies conducted at home and abroad. The content validity of the questionnaire was confirmed by a panel of experts (including 9 university professors 
Table 1. Ratio of each village in the total sample size (Source: Research Findings, 2017)

\begin{tabular}{|c|c|c|c|c|c|c|c|}
\hline Village & $\begin{array}{l}\text { Number of } \\
\text { households }\end{array}$ & $\begin{array}{l}\text { Percent } \\
\text { share }\end{array}$ & Ratio & Village & $\begin{array}{l}\text { Number of } \\
\text { households }\end{array}$ & $\begin{array}{l}\text { Percent } \\
\text { share }\end{array}$ & Ratio \\
\hline Davarijan & 48 & 3.13 & 10 & Azizabad & 92 & 6.00 & 18 \\
\hline Gousheh & 57 & 3.72 & 11 & Aliabad & 0 & 0.00 & 0 \\
\hline Marvak & 55 & 3.59 & 11 & Laban-e Sofla & 53 & 3.46 & 11 \\
\hline Dokhaharan & 9 & 0.59 & 2 & Kagheh & 271 & 17.68 & 54 \\
\hline Hamyaneh & 40 & 2.61 & 8 & Daichi & 70 & 4.58 & 14 \\
\hline Yazdegerd & 18 & 1.17 & 4 & Alamabad & 100 & 6.52 & 20 \\
\hline Poushkeshan & 131 & 8.55 & 26 & Ghaziabad & 6 & 0.39 & 1 \\
\hline Laban-e Bala & 110 & 7.18 & 22 & Kulabad & 59 & 3.58 & 12 \\
\hline Azna & 162 & 10.57 & 32 & Kalanganeh & 178 & 11.61 & 36 \\
\hline Jahanabad & 25 & 1.63 & 5 & Total & 1539 & 100 & 306 \\
\hline Darreh Tang & 55 & 3.59 & 11 & - & - & - & - \\
\hline
\end{tabular}

Table 2. Reliability of components used in the research

\begin{tabular}{|c|c|c|c|c|c|}
\hline \multicolumn{2}{|c|}{ Socio-cultural and economic dimensions } & \multicolumn{2}{|c|}{ Socio-cultural dimension } & \multicolumn{2}{|c|}{ Economic dimension } \\
\hline Number of items & Cronbach's alpha & $\begin{array}{c}\text { Number of } \\
\text { items }\end{array}$ & $\begin{array}{c}\text { Cronbach's } \\
\text { alpha }\end{array}$ & $\begin{array}{c}\text { Number of } \\
\text { items }\end{array}$ & $\begin{array}{c}\text { Cronbach's } \\
\text { alpha }\end{array}$ \\
\hline 131 & 0.922 & 72 & 0.854 & 59 & 0.910 \\
\hline
\end{tabular}

in this field) and conducting a pilot study. Moreover, its reliability was assessed using Cronbach's alpha method. This coefficient indicates the degree of overlap of different test items measuring a feature. The alpha ranges within 0-1 with a higher score showing more reliability. Cronbach's alpha $>0.7$ is considered desirable and acceptable. The alpha coefficient in the questionnaire used in the present research is presented in Table (2) in the appendix.

The one-sample t-test was used to investigate the economic and socio-cultural resilience of rural settlements in Silakhor rural district. Moreover, the Pearson correlation test was utilized to investigate the relationship between socio-cultural resilience and economic resilience. One-sample ttest is a parametric test which is used to compare the mean value obtained at different levels.

In this regard, this test was used considering the normal distribution of the sample and the purpose of the study. To assess the resilience of rural settlements in Silakhor district, the mentioned test was performed at a 95\% confidence level. Pearson correlation was used to investigate the relationship between socio-cultural resilience and economic resilience since the obtained data were ranked, the sample consisted of more than 120 people, and data were normal.

\section{Study area}

Silakhor is a rural district in Silakhor District, Dorud County, Lorestan Province. It is located at
49 degrees 51 minutes east longitude, 33 degrees 23 minutes north latitude. At the 2006 census, its population was 5,162 , in 1,539 families. Silakhor is located in $70 \mathrm{Km}$ distance from Dorud in Lorestan province in the foothills of the Zagros Mountains between Dorud and Borujerd. Due to abundant access to water and fertile soil, we are witnessing the most ancient settlements in this rural district. This district has large open areas which were inhabited by the largest populations in permanent settlements in ancient times (24). Figures 2 and 3 in the appendix indicate the political status of this rural district in the political divisions of the country and the distribution of the studied villages based on population.

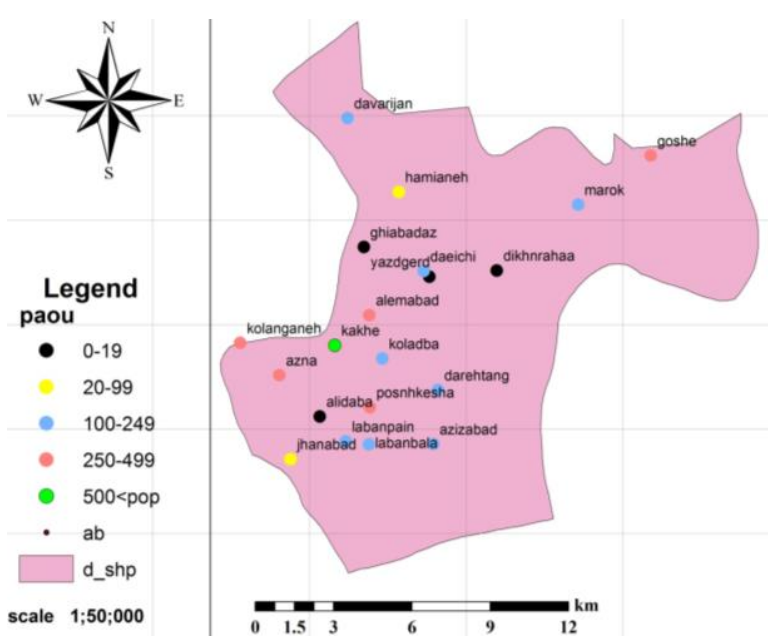

Figure 2. Political position of the rural district in the political divisions of the country 


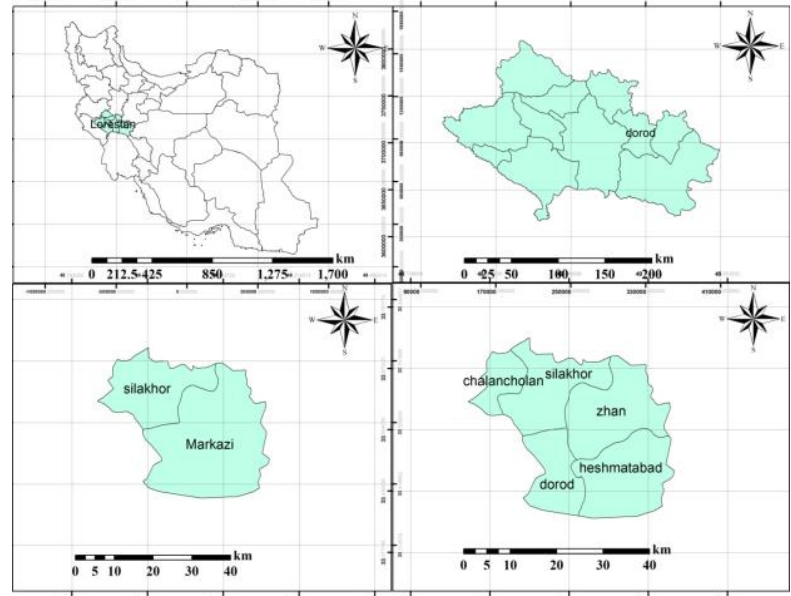

Figure 3. Distribution of studied villages based on population (Source: Research findings, 2017)

\section{Findings}

\section{A) Individual characteristics}

The mean age of the respondents was reported as 47.36 years, and the highest frequency was observed in the age group of 3-45 years. In terms of education level, the highest frequency (32.1\%) was detected in respondents with high school education. Furthermore, the research results showed that in terms of employment, more than $50 \%$ of participants were active in the agricultural sector (farmer and stockbreeder). In this regard, the highest frequency was related to farmers (147 and 149 cases were engaged in the mentioned job before and after the earthquake, respectively).

The study of indicators used to assess resilience in Table (3) shows that in the sociocultural dimension, the highest mean score $=3.31$ was related to "beliefs and religion", while the lowest mean score $=2.82$ was detected in "indigenous skills and knowledge". Moreover, in the economic dimension, the highest mean score $=4.07$ was reported in bank resource utilization, while the lowest mean score $=2.66$ was related to employment. The results of the descriptive statistics of the research indicators are listed in Table 3 in the appendix.

\section{B) The economic resilience of the region}

One sample t-test was utilized to assess and recognize the status of economic resilience in the villages of Silakhor rural districts. In this test, the value of 3 demonstrated the numerical optimization of the test item. The economic dimension of resilience in this study was obtained from combining such variables as economic capital and assets, employment, cost and income, damage, capacity and ability to compensate for

Table 3. Resilience indices among households in Silakhor district (Source: Research Findings, 2017)

\begin{tabular}{cccccc} 
& & & Combination of & \multicolumn{3}{c}{$\begin{array}{c}\text { Descriptive statistics } \\
\text { Row }\end{array}$} & Indicator & scales & Mean & $\begin{array}{c}\text { Standard } \\
\text { deviation }\end{array}$ & $\begin{array}{c}\text { coefficient of } \\
\text { variation }\end{array}$ \\
\cline { 4 - 6 } 1 & Education and awareness & Mean of 7 items & 3.1 & 0.59 & 19 \\
2 & Health & Mean of 16 items & 3.16 & 0.49 & 15 \\
3 & Sense of belonging & Mean of 15 items & 3.26 & 0.52 & 16 \\
4 & Beliefs and religion & Mean of 9 items & 3.31 & 0.8 & 24 \\
5 & Indigenous knowledge and skill & Mean of 4 items & 2.82 & 0.78 & 28 \\
6 & Race and ethnicity & Mean of 7 items & 3.3 & 0.54 & 17 \\
7 & Social capital & Mean of 14 items & 2.86 & 0.49 & 17 \\
8 & Economic capital and assets & Mean of 12 items & 2.77 & 0.59 & 21 \\
9 & Employment & Mean of 14 items & 2.66 & 0.52 & 20 \\
10 & Cost and revenue & Mean of 8 items & 2.95 & 0.58 & 20 \\
11 & Loss & Mean of 5 items & 2.96 & 0.74 & 25 \\
12 & Capacity and ability to compensate the loss & Mean of 6 items & 3.05 & 0.85 & 28 \\
13 & Ability to return to employment and income & Mean of 5 items & 2.86 & 0.73 & 26 \\
14 & Use of bank resources & Mean of 7 items & 4.07 & 0.68 & 17 \\
\hline
\end{tabular}


the loss, ability to return to satisfactory working conditions and income, as well as the use of banking resources. The results of the above test are displayed in Table (4) in the appendix.

The results depicted in Table (4) regarding the economic resilience in the villages of Silakhor district demonstrated that in the economic dimension, only the village of Kalanganeh had a positive t-statistic higher than \pm 1.96 as the critical value of $\mathrm{t}$. Therefore, it can be concluded that the abovementioned village is resilient. In this regard, the t-statistic was negative and exceeded the critical value of $t( \pm 1.96)$ in the villages of Azna, Alamabad, Laban-e Bala, Azizabad, and Jahanabad indicating the low resilience of these villages in the economic dimension.

The mean of other villages was somewhat equal and close to the mean of the test (3), with no significant difference. It can be stated that these villages are somewhat resilient in this regard. In general, the rural district under the study with the mean score close to the mean of the test (3) is somewhat resilient in the economic dimension.

\section{C) Socio-cultural resilience status of the region}

One-sample t-test was used to study and recognize the socio-cultural resilience status in the villages of Silakhor district. The sociocultural dimension of resilience in this study was obtained from combining such variables as education and awareness, health, sense of belonging, indigenous skills and knowledge, religion, race and ethnicity, and social capital. The results of the abovementioned test are presented in Table (5) in the appendix.

The results depicted in Table (5) regarding the socio-cultural resilience in the villages of Silakhor district demonstrate that in sociocultural dimension only Dokhaharan had a negative t-statistic of -9.19 which was higher than \pm 1.96 as the critical value of $t$. Therefore, it can be concluded that the abovementioned village had low resilience in social dimension. In this regard, t-statistics for Darreh Tang (2.78), Gousheh (2.7), Kulabad (3.2), Azizabad (6.27), Poushkeshan (2.74), Azna (3.66), and Kagheh (7.82) was positive higher than \pm 1.96 as the critical value of $t$. It pointed to the resilience of the abovementioned villages in the social-cultural dimension.

In this regard, the mean score of other villages was to some extent equal and close to the mean of the test (3) with no significant difference suggesting that these villages are somewhat

Table 4. Assessing the status of economic resilience in the villages of Silakhor rural district based on one-sample t-test (Source: Research Findings, 2017)

\begin{tabular}{|c|c|c|c|c|c|c|c|}
\hline \multirow{3}{*}{ Village } & \multicolumn{6}{|c|}{ Test value $=\mathbf{3}$} & \multirow{3}{*}{ Village evaluation } \\
\hline & Mann & Standard & t.yoluo & D-xolue & \multicolumn{2}{|c|}{$95 \%$ confidence interval } & \\
\hline & vieain & deviation & tevalue & P-value & Lower bound & upper bound & \\
\hline Davarijan & 2.77 & -0.22 & -1.12 & 0.288 & -0.67 & 0.22 & Somewhat resilient \\
\hline Dokhaharan & 3.01 & -0.37 & 0.03 & 0.978 & -3.99 & 4.01 & Somewhat resilient \\
\hline Yazdgerd & 2.62 & -0.37 & -0.79 & 0.486 & -1.86 & 1.12 & Somewhat resilient \\
\hline Jahanabad & 2.67 & -0.32 & -2.81 & 0.048 & -0.64 & -0.01 & Low resilience \\
\hline Hamyaneh & 2.94 & -0.05 & -0.49 & 0.635 & -0.30 & 0.2 & Somewhat resilient \\
\hline Laban-e Sofla & 2.89 & -0.10 & -0.94 & 0.368 & -0.34 & 0.13 & Somewhat resilient \\
\hline Darreh tang & 3.02 & 0.02 & 0.43 & 0.67 & -0.10 & 0.15 & Somewhat resilient \\
\hline Marvak & 2.98 & -0.01 & -0.17 & 0.866 & -0.24 & 0.22 & Somewhat resilient \\
\hline Gousheh & 2.99 & -0.01 & -0.05 & 0.957 & -0.37 & 0.36 & Somewhat resilient \\
\hline Kulabad & 3.01 & 0.01 & 0.28 & 0.78 & -0.08 & 0.11 & Somewhat resilient \\
\hline Daichi & 2.65 & -0.34 & -1.9 & 0.079 & -0.72 & 0.04 & Somewhat resilient \\
\hline Azizabad & 2.67 & -0.32 & -2.26 & 0.037 & -0.63 & -0.02 & Low resilience \\
\hline Alamabad & 2.63 & -0.36 & -3.19 & 0.005 & -0.6 & -0.12 & Low resilience \\
\hline Laban-e Bala & 2.73 & -0.26 & -2.34 & 0.029 & -0.49 & -0.02 & Low resilience \\
\hline Poushkeshan & 3.06 & 0.06 & 1.93 & 0.064 & -0.01 & 0.13 & Somewhat resilient \\
\hline Azna & 2.89 & -0.1 & -2.96 & 0.006 & -0.17 & -0.03 & Low resilience \\
\hline Kanganeh & 3.12 & 0.12 & 4.68 & 0.000 & 0.06 & 0.17 & Resilient \\
\hline Kaghe & 3.02 & 0.02 & 1.3 & 0.199 & -0.01 & 0.07 & Somewhat resilient \\
\hline Aliabad & 2.84 & \multicolumn{5}{|c|}{ Insufficient sample } & - \\
\hline Ghaziabad & 3.1 & \multicolumn{5}{|c|}{ Insufficient sample } & - \\
\hline
\end{tabular}


resilient in this regard. It is worth noting that the positive $\mathrm{t}$-statistic higher than -1.96 is indicative of better resilience, while negative t-statistic less than -1.96 suggests less resilience. In general, the rural district under the study village with the mean score of higher than the mean score of the test (3) is socio-culturally resilient.

\section{D) Assessment of the relationship between socio- cultural resilience and economic resilience}

Pearson correlation was used to investigate the relationship between socio-cultural resilience and economic resilience since the obtained data in both groups were ranked, the sample consisted of more than 120 people, and data were normal. The results are listed in Table (6) in the appendix. The results illustrated in Table (6) which examined the relationship between economic resilience and social resilience demonstrated that the abovementioned test was performed with the decision criterion or test level of $0.01 \%$. According to the obtained results regarding the correlation between economic and social resilience, the correlation coefficient was calculated at $0.420(\mathrm{P}<0.00)$ which points to the existence of a significant relationship in this regard. Therefore, it can be said with $99 \%$ confidence that there is a positive and significant relationship between economic resilience and social resilience. Figure 4 shows the correlation between economic and social resilient.

Based on the obtained results, it can be argued that there is a direct relationship between economic and socio-cultural resilience signifying that socio-cultural resilience improves with an increase in economic resilience. In the regions with more educated residents, savings and capital assume more importance. Therefore, enhanced knowledge and awareness increase capital and assets, which in turn, increases the level of resilience. Furthermore, regions with healthy residents are able to move on and bounce back from the stressful experiences of disasters quickly and effectively and have a high capacity to

Table 5. Assessment of social resilience in villages of Silakhor rural district based on one-sample t-test (Source: research findings, 1396)

\begin{tabular}{|c|c|c|c|c|c|c|c|}
\hline \multirow[b]{2}{*}{ Village } & \multicolumn{6}{|c|}{ Test value $=\mathbf{3}$} & \multirow{2}{*}{$\begin{array}{l}\text { Evaluation of } \\
\text { village }\end{array}$} \\
\hline & Mean & SD & t-statistic & P-value & $\begin{array}{l}95 \% \text { confide } \\
\text { Lower bound }\end{array}$ & $\begin{array}{l}\text { nce interval } \\
\text { Upper bound }\end{array}$ & \\
\hline Davarijan & 2.9 & -0.09 & -1.15 & 0.278 & -0.29 & 0.09 & Somewhat resilient \\
\hline Dokhaharan & 2.86 & -0.13 & -9.19 & 0.069 & -0.32 & 0.05 & Low resilience \\
\hline Yazdgerd & 2.83 & -0.16 & -0.5 & 0.651 & -1.24 & 0.9 & Somewhat resilient \\
\hline Jahanabad & 2.86 & -0.13 & -0.63 & 0.558 & -0.72 & 0.45 & Somewhat resilient \\
\hline Hamyaneh & 3 & 0.00 & 0.007 & 0.995 & -0.3 & 0.45 & Somewhat resilient \\
\hline Laban-e Sofla & 2.96 & -0.003 & -0.34 & 0.735 & -0.28 & 0.3 & Somewhat resilient \\
\hline Darreh tang & 3.13 & 0.13 & 2.78 & 0.019 & 0.02 & 0.2 & Resilient \\
\hline Marvak & 3.01 & 0.01 & 0.15 & 0.877 & -0.22 & 0.25 & Somewhat resilient \\
\hline Gousheh & 3.35 & 0.35 & 2.7 & 0.022 & 0.06 & 0.25 & Somewhat resilient \\
\hline Kulabad & 3.18 & 0.18 & 3.2 & 0.008 & 0.05 & 0.64 & Resilient \\
\hline Daichi & 3.1 & 0.1 & 0.67 & 0.509 & -0.23 & 0.3 & Somewhat resilient \\
\hline Azizabad & 3.29 & 0.29 & 6.27 & 0.000 & 0.19 & 0.45 & Resilient \\
\hline Alamabad & 2.9 & -0.09 & -0.84 & 0.407 & -0.34 & 0.39 & Somewhat resilient \\
\hline Laban-e Bala & 2.96 & -0.03 & -0.56 & 0.577 & -0.15 & 0.14 & Somewhat resilient \\
\hline Poushkeshan & 3.12 & 0.12 & 2.74 & 0.011 & 0.03 & 0.08 & Resilient \\
\hline Azna & 3.16 & 0.16 & 3.66 & 0.001 & 0.07 & 0.22 & Resilient \\
\hline Kanganeh & 3.27 & 0.27 & 8.2 & 0.000 & 0.2 & 0.25 & Resilient \\
\hline Kaghe & 3.17 & 0.17 & 7.82 & 0.00 & 0.13 & 0.34 & Resilient \\
\hline Aliabad & 2.74 & & & Insufficier & sample & & - \\
\hline Ghaziabad & 2.72 & & & Insufficier & sample & & - \\
\hline
\end{tabular}

Table 6. Correlation coefficients of the Pearson test regarding economic and social resilience (Source: Research Findings, 2017)

\begin{tabular}{|ccccc}
\multicolumn{2}{c}{ Correlation } & \multicolumn{3}{c}{$\begin{array}{c}\text { Statistical indicators } \\
\text { Correlation coefficient }\end{array}$} \\
\hline Economic resilience & Social resilience & 308 & 0.420 & 0.000 \\
\hline
\end{tabular}




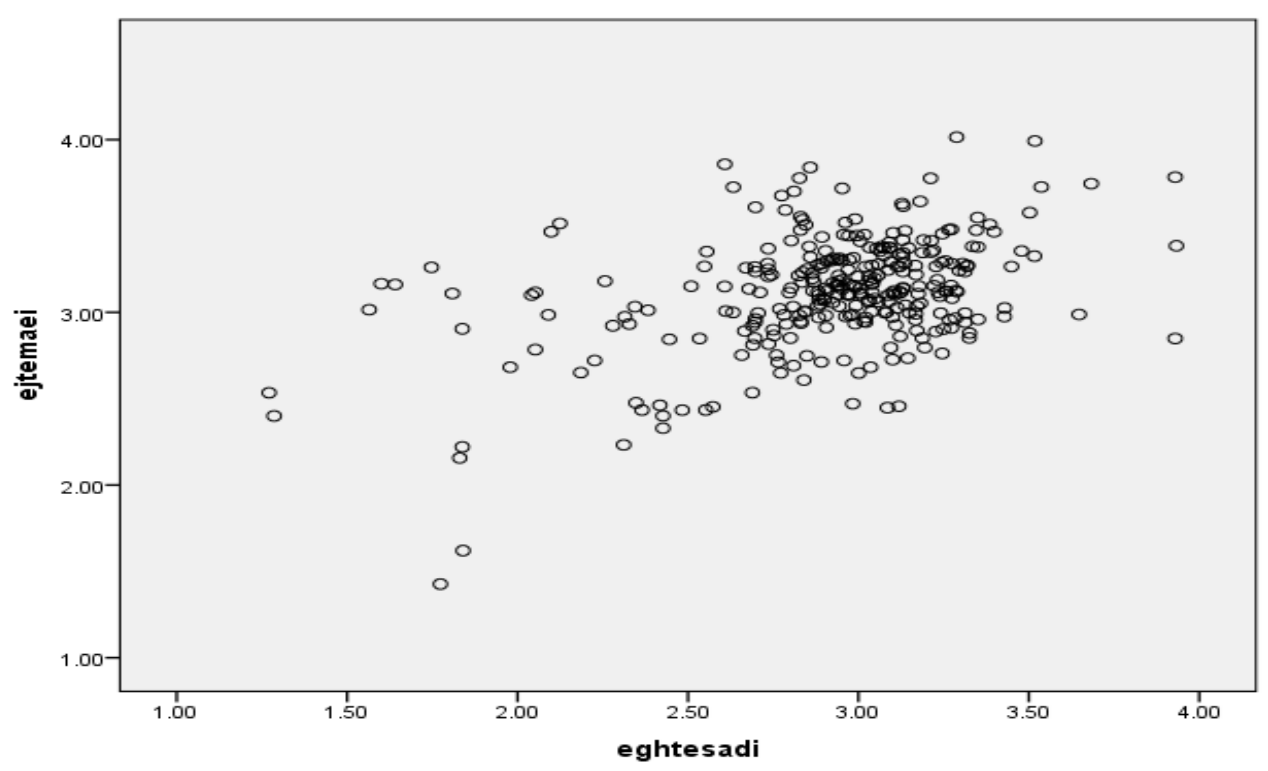

Figure 4. Correlation between economic and socio-cultural resilience (Source: Research findings, 2017)

compensate for disasters. This denotes the relationship of health with the capacity to return and compensate. Indigenous skills and knowledge and a sense of belonging will increase the demand for loans to generate more employment and income after the disaster. Therefore, it leads to the conclusion that there is a positive and significant relationship between economic resilience and socio-cultural resilience.

\section{Discussion and Conclusion}

Global experiences, such as the Asian tsunami and Hurricane Katrina, show that despite the implemented preventive measures, the consequences of disasters cannot be thoroughly controlled. Nonetheless, the capacity and ability of residents to withstand and survive in case of a disaster can be improved. Today, the assessment and increase of resilience against natural disasters have come into focus. In this regard, the simultaneous and reciprocal movement of sustainable development and disaster management to increase resilience has provoked heated discussion.

Accordingly, it is of paramount importance to assess and increase the resilience of human and environmental systems against natural disasters in order to achieve sustainable development. Therefore, to cope with natural disasters, it is necessary to investigate the resilience of rural settlements. The recognition of the economic and social factors affecting the resilience of rural settlements and the relationship between them enables us to develop practical approaches to strengthen and improve them.

The results of assessing socio-cultural resilience status showed that the resilience of the rural area under the study is favorable. Moreover, Dokhaharan village has a low level of sociocultural resilience, and the villages of Darreh Tang, Gousheh, Kulabad, Azizabad, Poushkeshan, Azna, and Kagheh have a good social and cultural resilience.

In this regard, the mean of other villages was somewhat equal and close to the mean score of the test (3) with no significant difference. Therefore, it can be stated that these villages are somewhat resilient in this regard. In addition, the results revealed that only the village of Kalanganeh has good resilience, and the villages of Azna, Alamabad, Labane- Bala, Azizabad, and Jahanabad have low resilience in the economic dimension.

The mean of other villages was somewhat equal and close to the mean score of the test (3) with no significant difference. Therefore, it can be concluded that these villages are somewhat resilient in this regard. In general, the studied rural settlements are somewhat resilient. The results of examining the relationship between socio-cultural and economic resilience denoted with $99 \%$ confidence that there is a positive and significant relationship between economic and social resilience.

In general, numerous studies have been 
conducted to assess the resilience of rural areas; therefore, the present study confirmed the findings gained in previous studies, some of which were mentioned in the literature review section. Moreover, it emphasized that natural disasters, such as floods, earthquakes, and droughts, destroy economic foundations (capital and assets, agricultural lands, and residential buildings). Consequently, they exert a significant impact on the economy of rural areas leading to rural depopulation and complete abandonment of villages.

Therefore, it is necessary to be aware of the resilience status of rural settlements. The current research differs from other studies since it not only assessed the socio-cultural and economic resilience of rural settlements but also examined the relationship between socio-cultural and economic resilience. According to the results of the present study which has examined the factors affecting economic and socio-cultural resilience, it has been sought to express suggestions based on these factors and variables to strengthen the resilience of Silakhor rural district.

- Optimal performance of banks and financial institutions to provide low-interest loans in the event of disasters and proper allocation of government funds among the affected people to increase resilience and accelerate recovery.

- Development of sustainable economic activities in the region by providing employment facilities and trying to attract investment to diversify economic activities in order to increase the capacity and financial ability of people to compensate for the damages and losses.

- The devotion of special attention to social networks and local institutions and the issue of trust, which is a hidden asset and can be effective in reconstruction programs (People's participation and the use of person-centered process).

- More assiduous attention on the part of officials and people to economic dimension to increase resilience and reduce vulnerability given that rural settlements in the study showed a low level of economic resilience.

- Increasing the capacity of local institutions and groups and encouraging people to cooperate and assist with local institutions in order to intervene in their own destiny and defend the community in times of crisis and disasters.

- More careful attention on the part of people and officials to make use of people's participation, as well as local skills and knowledge to bounce back after disasters.

\section{Acknowledgments}

Special thanks to the villagers and respondents for their patience in answering the questions of the questionnaire and also for the guidance of my esteemed teacher.

\section{Conflict of Interests}

No financial support has been provided for this research.

\section{References}

1. Saemipour H, Ghorbani M, Malekian A. Evaluating local beneficiary's resilience encountered with extended drought condition (Case study: Nardin village, Mayamey county, Semnan province). Journal of Rangeland Science 2018; 12(1): 62-72. [In Persian].

2. Mirlotfi M, Mohammadzairad T. Investigating the role of crisis management in sustainable rural development in Sistan region. National Conference on Civil and Architecture with a Sustainable Development Approach, Shirvan, Iran; 2015; P.110. [In Persian].

3. Ghanavati E, Khani S, Abdoli A. Empowerment of urban crisis management to reduce natural disasters (earthquake), case study: Khorramabad city. Natural Geography 2009; 1(4): 15-23. [In Persian].

4. Bazrafshan J, Toulabi Nejad M. Spatial analysis of variation differences in urban and rural areas against natural hazards (case study: Pol Dokhtar Township). J Rural Stud 2018; 9(1): 116-7. [In Persian].

5. Ghanbari S, Hassani Nejad A, Najafi M, Shayan M. The role of rural producer cooperative in reducing the effects of environmental hazards (case study: Ghurtan village in Isfahan). J Natural Environ Hazards 2016; 5(7): 29-46. [In Persian].

6. Datar A, Liu J, Linnemayr S, Stecher C. The impact of natural disasters on child health and investments in rural India. Soc Sci Med 2013; 76: 83-91.

7. Madrigano J, Chandra A, Costigan T, Acosta JD. Beyond disaster preparedness: building a resilienceoriented workforce for the future. Int J Environ Res Public Health 2017; 14(12): 1563.

8. Ainuddin S, Routray JK. Community resilience framework for an earthquake prone area in Baluchistan. Int J Disaster Risk Reduct 2012; 2: 25-36.

9. Ramezanzadeh Lesboui M, Asgari A, Badri S A. Infrastructures and resiliency to natural disasters with emphasis on flood the case: typical Tourism Regions in North of Iran (Cheshmekile \& 
Sardabrud). J Spatial Anal Environ Hazards 2014; 1(1): 35-52. [In Persian].

10. Rezaei M. Evaluating the economic and institutional resilience of urban communities to natural disasters using promethee method case study: Tehran districts. Emerg Manag 2013; 2(3): 25-36. [In Persian].

11. SadeghlooT, Sajasi Gheidari H. Survey relationship between rural settlement livability and rural resilience in front of natural disaster in rural areas of Maraveh Tappeh and Palizan County. J Emerg Manag 2015; 3(2): 37-44. [In Persian].

12. Bank CI. International bank for reconstruction and development. Washington DC: The World Bank; 2017. P. 204-33.

13. Zhou H, Wan J, Jia H. Resilience to natural hazards: a geographic perspective. Natural Hazards 2010; 53(1): 21-41.

14. Kusumastuti RD, Husodo ZA, Suardi L, Danarsari DN. Developing a resilience index towards natural disasters in Indonesia. Int J Disaster Risk Reduct 2014; 10: 327-40.

15. Klein RJ, Nicholls RJ, Thomalla F. Resilience to natural hazards: how useful is this concept? Global Environ Change Part B Environ Hazards 2003; 5(1): 35-45.

16. Bastaminia A, Rezaie MR, Saraie MH. Explaining and analyzing the concept of resiliency and its indicators and frameworks in natural disasters. Disaster Prev Manag Knowl 2016; 6(1): 32-46. [In Persian].
17. Parvaresh Z. Measuring the resilience of new urban communities in facing natural hazards case study: new towns in Isfahan City. [Master Thesis]. Tehran: Shahid Beheshti University; 2012. [In Persian].

18. Shokri FP. Spatial analysis of resilience of Babol regions to environmental hazards. J Phys Dev Plan 2017; 2(6): 27-44. [In Persian].

19. Eftekhari AR, Mousavi SM, et al. Analysis of the role of livelihood diversity to rural household resilience in drought condition: case study of the drought exposed areas of Isfahan province. Rural Res 2014; 5(3): 639-62. [In Persian].

20. Ramezanzadeh Lesboui M. Explaining the socioeconomic structure of residential residents responding to natural disasters with emphasis on flood. [Master Thesis]. Tehran: Tehran University; 2013. [In Persian].

21. Kafle SK. Measuring disaster-resilient communities: a case study of coastal communities in Indonesia. J Busin Continuity Emerg Plan 2012; 5(4): 316-26.

22. Iranian Statistics Center. Population and housing census, culture of villages. Tehran: Iranian Statistics Center; 2016. [In Persian].

23. Arouri M, Nguyen C, Youssef AB. Natural disasters, household welfare, and resilience: evidence from rural Vietnam. World Dev 2015; 70: 59-77.

24. Census results. Statistical Center of Iran. Available at: URL: ttps://www.amar.org.ir/; 2016. 